\title{
'Meyer-Neldel Rule': True History of its Development and its Intimate Connection to Classical Thermodynamics
}

\author{
E.B. Starikov ${ }^{1,2, *}$ \\ ${ }^{1}$ Institut für Theoretische Festkörperphysik, Universität Karlsruhe (KIT), D-76128 Karlsruhe, Germany \\ ${ }^{2}$ Department of Physical Chemistry, Chalmers University of Technology, SE-412 96 Gothenburg, Sweden
}

\begin{abstract}
The history of the Meyer-Neldel rule's development and the initial collective efforts toward its comprehension have been described here. The whole story gives a nice occasion to trigger thorough analysis of the basic thermodynamic laws and looking for the true sense of the entropy notion.
\end{abstract}

Keywords: Entropy, Enthalpy, Compensation, Thermodynamics, Nanoscale.

\section{INTRODUCTION}

At the beginning of this year the 'Monatshefte für Chemie' has published a special issue devoted to the chemistry and physics of 'the Meyer-Neldel rule' (MNR). The there editorial [1] clearly establishes the interconnection between the MNR phenomenon and the correlation between the activation energies and the activation entropies, when speaking about kinetics (the so-called iso-kinetic rule, IKR) or about equilibrium thermodynamics (the so-called iso-equilibrium rule, IER). Meanwhile, nowadays, such hotly debatable phenomena as IKR and IER (cf., e. g., the works [2-4] and the references therein) are normally associated with the names of Constable [5], Schwab and Cremer [6-8], Gapon [9], Zawadzki und Bretsznajder [10], whereas the names of Meyer and Neldel are only mentioned in connection with their sole paper [11] ... This might surely be OK, if there would be no trace of the real cloud of publications on the theme by Dr. Wilfried Meyer, as well as by his teacher (and chief, in the R\&D department of the OSRAM company), Dr. Ernst Friederich, plus a considerable number of the works, where the colleagues have genuinely tried to (re)observe what is presently called 'MNR' - and to physically-chemically explain the latter ... The present review aims at clarifying the true history of the MNR origination and the detailed analysis of the intimate interrelationship between the MNR and the conventional thermodynamics.

\section{WILFRIED MEYER'S WORK AND THE EARLIER} ATTEMPTS TO EXPLAIN HIS FINDINGS

Remarkably, Wilfried Meyer could somehow manage to publish his review paper [12] in the tragic

${ }^{*}$ Address correspondence to this author at the Institute for Theoretical SolidState Physics, University of Karlsruhe, D-76128 Karlsruhe, Germany;

Tel: +49 (0) 721-680-37-19; Fax: +49 (0) 721-608-70-40

E-mail: starikow@tfp.uni-karlsruhe.de year of 1944. This paper seems to be completely missed somehow, but it definitely deserves our attention.

The headline of his paper reads as follows: "Elektronenleitung in festen chemischen Verbindungen" (Electron Conductance in Solid-state Chemical Compounds). He starts by mentioning that he would like to deal with the "independent electron conductance", i. e. with the one, "which is related solely to the thermal energy in the solid state, but not triggered through some external impact, like incident light, e. g.". Then, he points out "both scientifically and technically outstanding progress" in the field he is describing, the general aspects of which have already been summarized in detail by Robert Wichard Pohl $[13,14]$. Further, Wilfried Meyer also mentions the general problem initially posed by Ernst Friederich [1528], namely the "fundamental issue concerning the prerequisites of why the electron conductance might occur in chemical compounds", which "was altogether rescinded in the recent years, in comparison to a number of special problems in the field". To this end, Meyer explains the main aim of his review paper as follows: "Here, the problem thus posed will be considered from somewhat more general standpoints".

The paper [12] consists of four more or less detailed chapters, namely:

a) "Leitfähigkeit, Gittersymmetrie und Art der chemischen Bindung"(Conductivity. Lattice Symmetry and Type of the Chemical Bonding)

b) "Unterteilung der Verbindungen mit Elektronenleitfähigkeit nach der Größe des Leitwertes" (Classification of the Compounds Having Electron Conductivity According to Their Conductivity Magnitudes) 
c) "Bedingungen für das Auftreten der Leitfähigkeit in festen chemischen Verbindungen" (Strings for the Occurrence of the Conductivity in Solid-state Compounds)

d) "Elektronenleitung in den Verbindungen, in denen das Metallion in mehreren Wertigkeitsstufen vorliegt' (Electron Conductivity in Compounds where the Metal lon is Present in a Number of Different Valency States)

As for the point a), Wilfried Meyer notices as follows: "Compounds stabilized in all the three Cartesian coordinates through intermolecular forces, the so-called van der Waals' complexes in molecular lattices, cannot be electrically conductive [15-28]. This is why, the organic compounds will not be considered here". The modern audience definitely wouldn't agree with such a conclusion, for the so-called "organic conductors, semiconductors and even superconductors" are in the mean time well known (cf., e. g., [29] and the references therein). However, such findings have come much-much later - so, this ought to completely excuse Wilfried Meyer ...

In the following Wilfried Meyer carefully analyzes Ernst Friederich's and his own results, together with the numerous data and findings by other authors (e. g., by numerous co-workers of R. W. Pohl, by Carl Tubandt, who, together with his wife, clearly belongs to Nazi victims - and by Bernhard Gudden, whom Stalinists killed, although he was never a Nazi functioner ...) including his 'MNR' finding of the "charge carrier work function $\varepsilon$ as a linear function of the specific conductance logarithm" [11,12,30-35] for different semiconductors. Interestingly, the well recognized nowadays results by $\mathrm{W}$. Meyer and $\mathrm{H}$. Neldel were independently confirmed by (later on - Prof. Dr.) Werner August Friedrich Franz Hartmann (in his PhD thesis at the TU Berlin - during that time - TH-BerlinCharlottenburg - when he was working in the R\&D lab of 'Siemens-Werke' in Berlin, as well as in his follow-up publication [36]) ...

W. Meyer has carefully and in detail analyzed many relevant works both in the German and in the English literature [37-57].

The main conclusion: Wilfried Meyer in his review paper [12] has definitely started to build up the true basis for the following detailed explanation of all the pertinent findings [11,30-35,36]. Still, he hasn't directly considered any interrelationship between the MNRtype findings and thermodynamics.
It is also very important to acknowledge, that W. Meyer could somehow manage to beat the deadly 'Wehrmacht' draft and thus to seamlessly continue his research work. Meanwhile, the latter was never purely academic [58]: he and E. Friederich - they both - were even granted a relevant patent [59]. Moreover, he could survive during the overwhelming postwar years and, although obviously he wasn't capable of actively continuing his research, he could still act as an anthologist of two book volumes named "Technischwissenschaftliche Abhandlungen der OSRAMGesellschaff' (Scientific-Technical Proceedings of the OSRAM-Society) (the volume 6. (1953) and the volume 7. Band (1958)) in collaboration with the Springer's publishing house. And, in the mean time, Prof.-Dr. W. A. F. F. Hartmann had not only just survived, but could also manage a really sheer scientific career in the GDR time, even in contempt of his huge problems with the there 'STASI' (the political police) ...

... Meanwhile, the findings of $W$. Meyer and $H$. Neldel, but still not those of W. A. F. F. Hartmann, had practically immediately attracted the professional attention of several other colleagues (interestingly, Dr. Hartmann had in his work (PhD thesis plus paper [36]) practically started trying to explain all the findings in question - but, as far as we know, hadn't continued this particular work later on in detail) ... Noteworthy in this connection are the works by Drs Georg Busch from Zürich [60-62] and J. H. Gisolf [63] (Dr. Gisolf was earlier involved into a collaboration with Prof. Dr. B. F. A. Gudden [64]).

Dr. Busch had carried out detailed experiments, to study electron conductivity in non-metallic compounds $[60,61]$ and subsequently published his summarizing report [62]. He had discussed in full detail the main findings of W. Meyer and criticized J. H. Gisolf for his conclusions:

"Observably, the rule by Meyer and Neldel seems to be true for the whole diversity of chemical compounds, so that one cannot exclude the possibility that such a rule might in effect be a general one. Still, our own data basically allow, first of all, to narrow down this rule to semiconductors with frozen-in structural defects.

Gisolf [63] has presented a quite different explanation of the Meyer-Neldel's rule. Specifically, it is based upon very specific assumptions which cannot be supported by the data described in the present report. To decide, whether such assumptions are true, would be possible after much more detailed experimental studies." 
... So, what was then the statement by J. H. Gisolf ?

In fact, he thought that: "the deviations in the biases of the Meyer's 'straight lines' could formally reflect some interconnection between the mobility of the charge carriers and the conductivity ..." [63].

In our opinion, both Busch and Gisolf have basically gone the same conceptual way, but underlined quite different aspects of the whole theme. On the one hand, it is throughout clear, that the electrical conductivity is dependent on the mobility of the charge carriers - and, on the other hand, on their concentration as well. But, altogether, the true main point here would be the competition among diverse microscopic factors, which either promote or thwart the macroscopically observed conductivity. But the most interesting remark belongs definitely to G. Busch, who had pointed out the possibility for the 'Meyer-Neldel's rule general validity' ... Such a standpoint has really come true with the time!

For example, already in a really short space of time after the publications by Gisolf and Busch a number of works had appeared, where the Meyer-Neldel rule has been applied both to the electric conductivity and to generalized diffusive processes not directly connected with the latter [65-70], with the gradual appreciation of the intimate interrelationship between the Meyer-Neldel rule and general thermodynamics - in particular, of the Meyer-Neldel rule's relevance to the 'enthalpy-entropy ratio' ...

The notion of 'entropy-enthalpy compensation' was that time already actively discussed, but still without any reference to the Meyer-Neldel rule (see, e. g., [71] and the references therein).

The notion of 'compensation', however, still without any direct reference to thermodynamics, has been brought into connection with the Meyer-Neldel rule in the work [72] - and its authors conclude: any detailed explanation of the mechanisms discussed here should await the true understanding of what is the exact sense of the Meyer-Neldel rule.

To this end, as we have already mentioned earlier, the logically consistent impact of the 'compensation' involved, ought to be some counterbalance among all the possible process-promoting and process-thwarting factors, which brings realistic, viable unidirectional (and - most probably - irreversible) processes to their logical termination - and the corresponding system taking part in it - into the true thermodynamic equilibrium ... Well, the modern readership might consider such statements odd and strange - and this ought to beg the immediate question: well, but how to reconcile such a standpoint with the well-known, conventional thermodynamics???

Herewith we would like to round off our short review and re-direct the interested readership to more detailed review papers on the theme (cf., e.g., $[73,74]$ ) - for we would now like to switch to a more detailed discussion about the thermodynamic aspects of the Meyer-Neldel rule. But, prior to that, we shall deal in a nutshell with a truly absorbing problem, namely:

\section{The Significance of the Meyer-Neldel-Rule for Chemistry}

An attentive reader might definitely exclaim here: All the above story deals but mainly with the solid-state physics, as it is - and what a kind of connection would exist between all this and chemistry ? ...

It has been noticed in the chemical literature already since a long time that the Meyer-Neldel's rule (MNR) might be considered a special, a specific case of a generalized compensation principle (cf. the review [73] and the references over there, e. g.). First of all, it concerns raws of similar findings for sets of different processes which are somehow related to each other (e. g., during kinetic studies on chemical reactions, one ought to deal with a certain set of reaction rate values, pre-exponential factors and activation energies, which are connected to each other, like ditto in the MNR cases, and obey the conventional MNR-equations (1) und (2)).

$$
\begin{aligned}
& \sigma=A e^{-\frac{\Delta E}{2 k T}} \\
& \log A=\alpha+\beta \Delta E,
\end{aligned}
$$

where $\sigma$ conventionally corresponds to conductivity (but in chemical kinetics - to reaction rate), $A$ stands for the pre-exponential factor, $\Delta E-$ for the activation energy, $k-$ for the Boltzmann constant and $T-$ for temperature.

And if we employ in this case the conventional Eyring-Polanyi- (or Arrhenius-van't-Hoff-) equation, we immediately recast Eqs (1) and (2) in the following equation for the enthalpy-entropy-compensation which, purely mathematically seen, actually describes a linear regression of enthalpy $H$ on entropy $S$ : 


$$
H=T_{c} S+a,
$$

where $T_{c}$ stands for the so-called "compensation temperature", whereas the regression constant $a$ is possesed of the energy dimensions.

For example, the work [75] suggests the following physical-chemical interpretation for Eq. (3) (however, without any detailed analysis or the proper references):

$\Delta H=T_{c} \Delta S+\Delta H_{r e s}$

where $\Delta H_{\text {res }}$ is introduced as the "enthalpy change of iso-entropic reaction". Would this be the actual sense of the empirical constant involved ? Here, we would like to consider this interesting problem in a bit more detail. In the work [76] we show that a valid, non-trivial enthalpy-entropy compensation ought to be a necessary and sufficient condition for the existence of some hidden thermodynamic cycle (namely, a Carnottype cycle). It is possible purely mathematically to partition such a cycle into a sum of infinitesimal Carnotcycles. For each of such partial cycles the both of the general thermodynamic laws in their differential form are true:

$d S=\frac{\delta Q}{T} ; \quad d U=\delta Q-p d V$

where the first of the both equations embodies the Second Law, so that the entropy $S$ is represented by the Clausius' formula - and the second equation describes the First Law. Here the $Q, U, p, V, \delta, d$ correspond to the warmth, internal energy, pressure, volume, the inexact (path-dependent) and the exact (path-independent) differential. As soon as we in Eqs (5) get rid of the inexact differential, we get the well known Clausius-Gibbs' equation:

$d U=T d S-p d V$

which we would like to integrate under the isobaricisothermic condition ( $p=$ const, $T=$ const), so that the pressure and the temperature would in effect correspond to the adjustable, controllable parameters of the system under study. To this end, the system's volume ought to be one of the main proper integration variables. And finally we arrive at the following result:

$U+p V=T S-T S_{\text {const }}+U_{\text {const }}$,

where Eq. (7) is immediately compatible with Eq (3), for $H=U+p V, a \equiv U_{\text {const }}-T S_{\text {const }}$ and $T \equiv T_{c}$. Therefore, the energy constant a in Eq (3) should have nothing to do with the enthalpy, but rather with the Helmholtz' free energy ... Hence, by and large, the physical sense of the entropy-enthalpy-compensation would consist in that during the process in question, the both thermodynamic potentials - the free energy (the potential of Helmholtz) and the free enthalpy (the potential of Gibbs) - come to be equal to each other.

\section{Physical-Chemical Sense of Enthalpy-Entropy- Compensation}

In fine: the Meyer-Neldel's rule has undeniably something to do with the entropy-enthalpycompensation. But is such a statement physically (chemically etc. etc.) sensible ? And what does the latter notion actually mean ? Does it have any valid meaning altogether - or, as many colleagues state, such a compensation ought to be a kind of 'pipe dream' ? The theme is utterly disputable - and the relevant debates are still going on [2-4,73-77]. But it is our firm belief that the compensations of such a kind are up to the hilt and intimately connected with the conventional thermodynamics - thus, we would like to reconstruct here the general logical train of thoughts leading to such a conclusion.

\section{The Basic Laws of Thermodynamics}

... Enthalpy (that is to say, energy), entropy - so, what immediately crosses one's mind? The two Basic Laws of thermodynamics, indeed. Their standard formulations are very well known from the pertinent modern course books, lecture scripts and/or from the Internet sources [78] as well.

There is a number of their different formulations which are well known and it is throughout clear that, although the Basic Laws are overwhelmingly general rules of the Nature AS A Whole, well outside the restricted area of thermodynamics, it is rather difficult to derive their actual practical sense from the available formulations. Apart from numerous diffuse references to some 'aggravating philosophic ambiguities', the conventional thermodynamic compendia and lecture scripts are also full of quite foggy deliberations like, e. g., 'reversibility/irreversibility' and 'equilibrium/nonequilibrium' ... Should all of this be really so 'bad for the digestion'?

As to the First Basic Law - its story is well known ... And concerning the Second Basic Law we read in a publication of Edwin Thompson Jaynes [79], the father of the "maximum entropy principle", the following wise words: 
"We are taught to think of the First Law of Thermodynamics as a basic law of physics, true of necessity in every case. But attempts to see the Second Law in this way (Kelvin, Clausius, Planck, Boltzmann and many others) never quite succeeded; and Gibbs (1875) recognized that its logic is different. He concluded that "the impossibility of an uncompensated decrease seems reduced to improbability", a remark that Boltzmann quoted 20 years later in the Introduction to his "Gastheorie".

Clausius saw the second law as a law of physics, but only a qualitative one - a kind of arrow to tell us in which general direction a process will go. Gibbs, while depriving it of that logical certainty, extended its practical application to serve the stronger purpose of quantitative prediction; to fill the logical void left by the great incompleteness of thermodynamic data. Out of all the different macroscopic behaviors permitted by the macroscopic data and the microscopic laws of physics, which should we choose as, not 'what musl happen', but only 'what will most likely happen'?

Since Gibbs' "Heterogeneous Equilibrium" (187578) the second law has been used in practice, not as a "law of physics", but as a principle of human inference; a criterion for resolving the ambiguities of incomplete data. In this Service it does indeed extract more information than could have been obtained from the data alone; not by magic but by combining the evidence of the data with the additional information contained in the entropy function.

In other words, Gibbs' use of the second law to predict equilibrium states was virtually identical in rationale with our present maximum-entropy inference.

The experimental confirmation of Gibbs' thermodynamic predictions, and the success of maximum-entropy predictions outside thermodynamics, are just two illustrations of the power of that rationale.

The above summarizes our general philosophical viewpoint; now we must justify it by examining those mysterious technical details, to show that there is not just a similarity of philosophy, but an identity of mathematical method."

... Still, we have now a bit more to do - namely, we would now like to try answering this eternal - already really wretched - questions, what is exactly the additional information contained in the entropy function', what is in fact the physical sense of this famous entropy notion.
First of all, we shall apply now to the assets of Felix Auerbach. He had in fact presented the rightest key to a successful solution of the problem posed above already long ago in his works [80-82]. Viz., he had point-blank described his detailed suggestions in his books $[81,82]$ - his descriptions are extremely clear-cut and pellucid even for the non-specialist audience they are even illustrated with lots of nice examples from the normal everyday life ...

One could trace the logics of Felix Auerbach's ideas as follows:

1. It is possible to formulate the First Basic Law following the works by Julius Robert von Mayer, James Prescott Joule and Hermann von Helmholtz in such a way that all the kinds of energy in the Nature are in a definite sense equivalent to each other. Otherwise, the World As A Whole would be governed only by a total chaos, and there would never be any space for more or less distinct order. Further, one could in principle understand the conservation of the Matter, of the Substance, also in terms of the energy conservation.

2. Along with this, all the natural manifestations are connected in that/those ways with changes, transformations, metamorphoses etc. etc., in such a way that the total quantity of the Matter, of the Substance, of the Energy still remains unchanged, according to the Basic Law. What is but being nevertheless changed, mind you, would only be the 'quality of the energy'.

3. This means: in fact, there ought to be not only the 'Conservation/Preservation Law', but also some kind of 'Variation Law' as well. Besides, a very important aspect of all the changes/metamorphoses in the world would be the availability of multiple, of a number of, logical possibilities for the outcomes/results of the changes in question, which are sometimes a priori difficult to apprehend/to conceive in detail. (Our remark: So, this is just how the notion of probability could naturally be taken into consideration !) ...

4. In the course of both spontaneous and enforced/perforced changes/metamorphoses, there are in most cases perceptible conciliations/levelings of some kind/type, so that there could practically be no way for 
'conservative processes' in the strict sense of the word, that is the processes running without any severance and at the same time continuously preserve their primary/pristine 'form'. Normally, the conventional processes are at least in some sense finite, constrained, restricted, distinctly confined. (Our remark: This is why, we might infer herefrom that the final states of such processes correspond to equilibria of the pertinent kind).

5. Thence the First Law, the 'Conservation Law', proscribes such 'perpetuum mobile'-processes that scoop the energy necessary to promote them out of nothing or blight the energy in a traceless way. And the Second Law, the 'Variation Law' in addition, ought to prohibit such 'perpetuum mobile'-processes that trigger infinite, unrestricted, truly conservative processes.

6. The bottom line is that, as realistic, finite processes go along, the energy necessary for their proceeding ought somehow to be 'dispelled', whereas the total amount of energy remains unchanged - and only the 'quality of the energy' is getting changed. The 'intensive', 'useful', 'active' energy is getting 'extensive', 'useless', 'passive' - whereas the former energy does not disappear - for it is being transformed into the accomplished useful work. And the energy conversion efficience in such processes would never reach $100 \%$ - just owing to the inevitable 'devaluation of the useful energy', as Carnot had shown.

7. And now the question arises as for the nature of the 'reversibility'. Our 'Mother Nature' is normally possessed of either absolutely irreversible - or only partially, only contingently reversible processes. To this end, the famous circular process of Carnot should be nothing more than his ingenious theoretical widget, just to make out the actual impact of the Second Basic Law.

8. In a nutshell: The above-mentioned degree of the energy 'distraction' or 'devaluation' could be dubbed - 'Entropy' - according to the works of Carnot, Clausius and Lord Kelvin, so that in the course of any realistic, finite process the entropy should increase - (Our remark: up to the 'point' where its impact finally manages to counterpoise the forces promoting the process under study.
This is just the logical way of how the latter comes to its natural end - and the whole system in consideration - to its equilibrium state).

Basically, similar ideas had been more or less simultaneously expressed not only by Felix Auerbach, the German physicist, but also by Frantishek (Franz) Wald, the Czech chemist [83] and by James Swinburne, the British engineer [84]. James Swinburne, when discussing the problem of 'What Entropy Is Not And What It Is' just to reveal the actual physical sense of this notion, had clearly stated as follows:

'... The difficulty with entropy is that it is a quantity whose increase denotes incurred waste, and it is thus very general, so that entropy is increased in different ways in different cases, and there is no one molecular change that corresponds with increase of entropy ...'.

\section{What is then the Authentic Physical Sense of the Entropy Notion?}

Altogether, Felix Auerbach had found a very apt, artistically minded description for the energy and entropy: 'The World Mistress (the energy) And Her Shadow (the entropy)'.

Was there any feedback to the Auerbach's address at all ?

What has immediately caught our eye, is the book by Werner Kollath 'Die Ordnung unserer Nahrung. Grundlagen einer dauerhaften Ernährungslehre' (The Order of Our Nurture. Foundations of a Durable Feeding Theory) [85]. Among other interesting topics, Werner Kollath analyzes Auerbach's ideas in detail und tries to place them in a row together with the ideas of other authors, like Jean Gerber, Norbert Wiener, Bernhard Bavink - withal, he is following the original suggestion of Auerbach, to replace the original notion of 'entropy' with that of 'ectropy' ... Interestingly, Auerbach's 'ectropy' is in effect awfully well correspondent to the notion of 'negentropy' by Erwin Schrödinger [86] und Leon Brillouin [87] (whereas the modern considerations concerning the latter notion are discussed in detail in [88], e. g.) ... Still, some deliberations in the work by Werner Kollath appear to be somewhat chaotic, as one might see from what follows [85]:

"So well known and recognized only the first law is, so well known but little understood is the second law, not among the physicists, but among the biologists and 
physicians." (Our remark: Werner Kollath wrote this in the years 1940-1970, but this still remains to be correct on the whole - and as concerns the physicistschemists - too, alas ! We shall come back to this point below in more detail. Claude Shannon, the pioneer of the Information Theory, as he seriously started to flirt with making use of the 'entropy' notion, had yet followed a suggestion (still valid up to date, a propos !) from the prominent mathematical physicist John von Neumann: „... nobody knows, what entropy in fact is, so one could always benefit from such a term choice in any debate.")

"It is hardly possible in fact to understand the following formulation without detailed explanation:

Nature has a marked tendency to increase entropy at the expense of ectropy. The entropy of the world tends to a maximum." (our remark: but this is yet nothing more than just a versicolour potpourri out of the ideas by R. Clausius und F. Auerbach !) ...

"Here, Auerbach might again be of help to us:

The energy ought to be incessantly succumbing to qualitative conversions and level transformations. And we might call this kind of variability 'tropism'. The trends of the latter could be ambiguous, to see it in a purely logical way - a conversion/transformation with clearly boosted external effects ought to be 'ectropic', or its impact is mainly internal - in such a case it might be considered 'entropic'.

Again, here we bump into a cliff of thinking.

How can the 'inward-facing' work - and this is just what 'entropy' ought to mean - be seeking its maximum ? (This would mean 'a concentration'. Yet just the opposite should be true).

To understand this, let us deal with the special case, which is also the most important for us, the heat energy. It's easy to understand that heat can be transferred only from a warmer to a colder place, so that the former is growing colder, and the latter is getting warmer. Finally, a compensation takes place. The process has come to a standstill.

Now, it is a fact frequently observed in the engineering science, that, for example, mechanical work can be completely converted into heat, but heat cannot be completely converted into mechanical work. There is always some remainder of heat, whereas the total sum of the latter is reduced, because some heat has still been used to perform a useful work.
What is heat then? One can define it as a 'uncoordinated or random motion of molecules'. Now, combining the latter statement with the previous deliberations: To get orderly movement out of disordered movement is equal to = mechanical work (in the case we discuss, regardless of any particular apparatus). Hence, in short, we may thus get order out of disorder.

But the law of entropy states that, in a closed system, the pursuit of a state of the greatest disorder prevails, or, in other words, the greatest possible balance - the reference to Norbert Wiener. (Our remarks: first of all, 'closed systems', 'ideal gas', etc. constitute nothing more than convenient theoretical idealizations - and, moreover, there is absolutely no clear logical bridge between the 'greatest disorder' and the 'greatest possible balance' ... However, this is not by any means the demur to the address of Werner Kollath or Norbert Wiener - this should be a serious objection to the true authors of such an unreasoning ...)

This condition of the greatest disorder and, respectively, balance - i. e., the lack of differences between the levels, leveling - is now known as 'entropy', and Boltzmann has transferred this idea to the universe as a whole and expressed the assumption that the Second Basic Law, as it is, also applies to the universe, so that the latter ought to head for the total heat-clutter, to an over-all general compensation, to an over-all leveling, indiscrimination, stoppage. He described such a final result as a 'heat death'. But it is also possible to represent this situation as a kind of 'chillness death'.

After Bavink, this old view of the heat 'death' isn't any more widely recognized.

Thus, the most strange assumption here would be to consider the whole Universe as a 'closed system'. Whatever one could think about this, even within our living rooms there are numerous open or semi-open systems - so should the Entropy Law accordingly be invalid for the latter? 'The technics of the whole world is down only as a whole' - posted by Norbert Wiener." ...

... Well, well, Felix Auerbach could definitely help us - but he somehow didn't manage to do so ... And the above mentioned quote is a blatant demonstration of how we can easily lose the logical thread ... But, to this end, Werner Kollath could still correctly locate at least one of the points where the logical thread had gone lost 
(cf. his discussion as to the 'chillness death' and 'closed systems' above). In the final analysis, we, the readership, have got a very colorful mixture of the ideas by Clausius, Boltzmann, Auerbach, Bavink ... So, how, please, should it be possible to cope with such a mess ? Well, aside from all this, Werner Kollath's book is definitely highly recommended!

Interestingly, whereas the logically clear deliberations by $\mathrm{F}$. Wald haven't largely been noticed, the James Swinburne's discourse had triggered very hot world-wide debates (not only outstanding British colleagues, like John Perry, James Swinburne, Oliver Heaviside, Oliver Lodge, have taken part, but also Max Planck from Germany, Henri Poincaré from France, as well as Sidney Armor Reeve from the USA) ...

The 'what is entropy' debate around the deliberations by James Swinburne is described in detail in the book about Oliver Heaviside [89]. He was actually only peripherally involved into a 'nasty squabble [89] (on the concept of entropy) between James Swinburne and John Perry' - well, that 'squabble' really was in itself 'nasty' enough [90-93] but Oliver Heaviside, together with Oliver Lodge, although their deliberations were reasonable enough, had obtained a really hard (and, in effect, unfair !) response from Max Planck [89,93].

Furthermore, an important topic intimately related to that entropy story was also discussed in German periodicals about during more or less the same time namely, the Second Basic Law [94-100].

After the address by Joseph Bertrand [94], Carl Neumann [95] had triggered the discussion by putting the following statement: "Today, as concerns this Second Basic Law, the opinions are coming diametrically apart. Some authors, for example, Gibbs, Duhem, as well as Planck tend to consider this Law as something unassailable, as a solid foundation for their 'High Billowing' theoretical buildings. Whereas other authors, however, like, for example, J. Bertrand, hold this record for a delusion, for a claim that has not even been tried all evidence obtained through no assurance probability". Then, he expresses his own standpoint which boils down to the following: 'The Second Basic Law is undoubtedly a very important problem to be treated seriously, but for the time being (by the end of the XIX-th century) there is a lack of its clear, unambiguous formulation, so that any application of such a law ought to be considered precarious' ...
This address had called several authors to action, Max Planck, Karl von Wesendonck, Otto Wiedeburg among them [96-101]. That discussion was extremely fair, unlike the British one, but, among the three named colleagues, only Max Planck had thrustfully and fruitfully continued the work on the correct formulation of the Second Basic Law and its application, for Otto Wiedeburg had passed away, whereas Karl von Wesendonck had for some own reasons quit the scientific community ... But right before his departure he had published a paper [101], where he tried to call the attention of the colleagues to the Swinburne's address [84], as well as to the address by the prominent German engineer, Hans Lorenz [102], which actually contains a kind of paraphrase of the Swinburne's conclusion:

“... we may conclude that an increase in system's entropy is always connected with any dissipation of energy within the system involved, and we denote such a conclusion as the Second Law of ThermoMechanics."...

Moreover, at the time being there was another physicist in Germany (he was originally from Kowno, now Kaunas, Lithuania), Max Bernhard Weinstein, who was also actively working on thermodynamics among other fields - and who formulated the foundations of thermodynamics as follows:

"The foundations of thermodynamics have panned out of the numerous experimental findings that the energy of heat might as such be transmutable into other energy types and obtained from the latter as well, plus, furthermore, that the transmutability of heat into other energy types and back is not unrestricted, but dependent on the particular circumstances under study. The first part of this statement had led to working out the First Basic Law of thermodynamics, whereas its second part had been transformed into the new concept presently known as the Carnot-Clausius' Law, or the principle of maximum entropy. In accordance with this, there are two Basic Laws of thermodynamics." [103].

... But all these clear and rational addresses have somehow fallen on deaf ears ...

Interestingly, the discourse by Franz Wald [83] (and, most probably, that by Felix Auerbach [81]) had produced the following reaction by the Swiss physicist and meteorologist, Jacob Robert Emden, who draws the following conclusion [104]: 
"As a student I read with advantage a small book by F. Wald entitled "The Mistress of the World and her Shadow". These meant energy and entropy. In the course of advancing knowledge the two seem to me to have exchanged places. In the huge manufactory of natural processes, the principle of entropy occupies the position of manager, for it dictates the manner and method of the whole business, whilst the principle of energy merely does the bookkeeping, balancing credits and debits."

The above address had attracted attention of two outstanding theoreticians, namely of Arnold Sommerfeld in Germany and Ryogo Kubo in Japan, who had considered it in detail in their works $[105,106]$ independently of each other. And their conclusion can be summarized as follows:

"The remarkable conclusion on the primacy of the entropy over the energy thus applies a fortiori.".

Well, the above idea seems to have been transformed into a kind of commonplace.

Indeed, we read in the book by the well-known German physicist, Hans-Dieter Zeh [107]:

"... The entropy gain is also the driving force behind all evolutionary processes."

Moreover, the prominent Soviet biophysicist, Mikhail Vladimirovich Volkenstein expresses withering criticism toward the ideas of Wald and Auerbach in his book [108]:

"So, Emden says that the entropy and energy - the shadow and the queen - must be swapped. As in the fairy tale by Hans Christian Andersen, "The Shadow", transformed into a beautiful play by Eugene Schwartz.

Such a metaphor - the queen and her shadow - is not too substantial. It is better not to use it, please, do call the energy and entropy neither queen, nor shadow. Still, entropy, as we see, is no less important than the energy. And in cosmology as well as in biology. That's because time flows from the past to the future."

Along with this, he presents a detailed discussion about some kind of "entropic forces", which "ought to govern the solubility of hydrophobic compounds in water". But, in effect, the latter representation cannot be verified by detailed physical-chemical studies, for the solubility of hydrocarbons in waters is demonstrating some kind of enthalpy-entropy compensation instead (Our remark: there was a usual verbal reaction of Soviet students, when something really important comes quite unexpectedly: 'кстати, o птичках', 'by the way, about the small birds', 'übrigens, was die Vögelchen anbelangt', 'par ailleurs, sur les petits oiseaux') [109]:

\section{"Conclusion}

(1) The enthalpy of solution of hydrocarbons in water has a large positive value at temperatures above $160^{\circ} \mathrm{C}$, where iceberg formation of water molecules surrounding solute molecules becomes negligible.

(2) The enthalpy of solution of hydrocarbon in water gradually diminishes with decrease in temperature due to a negative enthalpy of iceberg formation of the surrounding water molecules.

(3) The small or negative enthalpy of solution of hydrocarbons at room temperature results from a large positive enthalpy of mixing (decrease in hydrogen bonding interaction of adjacent water) and a large negative enthalpy of iceberg formation.

(4) The large negative standard entropy of solution also results from iceberg formation.

(5) Iceberg formation is somewhat similar to a liquidsolid phase change. Such a phase change always involves both an enthalpy and an entropy changes. It is not an entropy process.

(6) Solubility increases due to the iceberg formation. Namely, the actual solubility curve is shifted to higher concentration than the hypothetical solubility curve in which no iceberg formation occurs."...

The themes of the Second Basic Law, of entropy are still being discussed in the Russian special literature. For example, there is a book by a physicist Evgenij Grigorievich Oparin, entitled "Physical Foundations of Fuel-Free Energetics (Limitations of the Second Law of Thermodynamics)" [110]. After analyzing the long international history of thermodynamics, he draws practically the same conclusion as C. Neumann [95] already many years ago:

"There are numerous formulations of the Second Basic Law of thermodynamics. Some course 
transcripts reveal up to 18 wordings of it which are largely identical to each other. Still, each of them, as we know, is a postulate. There is no mathematical proof of the Second Basic Law based upon the known Laws of Nature which could be considered Absolute Truths at the present stage of the scientific research development."

A throughout similar situation has been humorously noticed by P. Th. Landsberg long ago in his book [111]:

"... one sees that an easily understood modification of the Kelvin-Planck formulation of the second law: Of the three kinds of perpetuum mobile only the third kind is possible. Or, more explicitly: Heat can be completely converted into work by taking a medium through a cyclic process if, and only if, that heat is withdrawn from a negative-temperature reservoir. Unfortunately this third kind of perpetuum mobile has not as yet been turned to use owing to the limited life of negativetemperature states." ...

On the other hand, the book by a Soviet engineer Georgij Nikolaevich Alekseev, entitled "Energy and Entropy" [112] is trying to logically develop the ideas by F. Wald and F. Auerbach. The central statement of this book can be put as follows:

"Energy and entropy - "The World Mistress And Her Shadow". Everything upon Earth emerges and develops thanks to the energy, everything collapses and dies with the increase of entropy. Energy serves as a source and a measure of the motion of matter and the action of forces. Entropy is a measure of their gradual extinction. But people have realized this only a little over a hundred years ago ..."

... Remarkably, there is but at least one book in the field of natural sciences [113], where the authors analyze in detail "the entropy as a measure of the 'value' of energy" and then manage to present a very handy formulation of the both Basic Laws of Thermodynamics:

1) "Basic Law: Energy can neither be created nor destroyed, so the energy satisfies a conservation law.

2) Basic Law: Entropy can never be destroyed, but may still be generated."

Well, 'friends may meet, but mountains never greet' ... To sum up: yes, of course, there must be some sensible physical counterparts of entropy - but what are they in fact?
So, what was then the main difficulty getting woven into the process of the Second Basic Law comprehension? Was it the absence of mathematical foundations ? Of course, not, not at all ! Both Clapeyron and Clausius have triggered the mathematical work which was carried out all over the world [114-116] and had its culmination in the work of C. Carathéodory $[117,118]$. Further, the work on the mathematical foundations wasn't over with Carathéodory's publications. Indeed, the important addition by Boltzmann and Planck, as concerns the probabilistic nature of the processes' irreversibility stemming from the atomic/molecular structure of the matter - could just be formally mathematically derived from theoretical statistics - without postulating the atomistic representation of the matter [119].

Apparently, the true problem consists instead in some special logical structure of the Second Basic Law, as E. T. Jaynes has mentioned [79] ...

In our opinion, the key to the problem's solution was given in the book by a prominent German theoretical physicist, Richard Becker [120], who had expressed this as follows:

"The provisions of the classical thermodynamics apply to processes taking place reversibly. We have discussed the significance of such a limitation when considering the Carnot cycle. Reversible ought to be only such processes that occur "infinitely slow." Meanwhile, any realistic process would be proceeding at a finite rate, therefore it should necessarily be irreversible. ... Moreover, such a realistic process is in any case associated with an increase in entropy.

In this case the conventional thermodynamics considers only reversible processes in which the entropy of any isolated system remains constant, whereas any realistic process should definitely be associated with an increase in entropy.

Thus, once an irreversible process is always associated with an increase in entropy, then the both phenomena would always occur at the same time. Still, just stating that "one of the both phenomena should be the cause of the other" does not in effect introduce anything new from the physical viewpoint. Nonetheless, the statement of the latter kind should be most accurate and complete to formulate the appropriate laws.

Indeed, with this in mind, one might say in such a case that either a) "entropy increases because the 
process is irreversible" or b) "irreversible process takes place because it is associated with an increase in entropy."

At the initial development stages of the theory of heat', mainly the former formulation was preferred. Recently, the latter standpoint has turned out to be more fruitful. According to this formulation, the trend expressed by the increase in entropy is considered as the "cause" of irreversible processes. You can talk about the "force" that drives the process. Within such an approach, one expects that the process under study should proceed the more rapidly, the higher the associated increase in entropy. Hence, we come to the assumption of a link between the increase in entropy and the rate of the process."

In fact, this discourse clearly shows how the logic might be re-arranged to produce reliably working practical rules at the expense of the physical sense. By inventing the notion of "entropic driving forces" which are definitely capable of serving as a useful, handy, practical and theoretical instrument in some particular cases, we consciously set aside the problem of clarifying the physical sense of the entropy notion ... Obviously, without such a clarity the notion of entropy belongs to one of the 'Altlasten der Physik' ('legacy issues of the physics') [121]:

\section{"Conceptual defects of the entropy notion:}

That the entropy is qualitatively detectable could be considered a definite progress, but it is not enough to satisfy the corresponding claim of a physicist. Physicists know that variables might only be considered defined, if it is possible to introduce direct or indirect methods for their quantification. Disturbing here is also the fact that it is seemingly difficult to assign any simple macroscopic feature to such an undoubtedly macroscopically definable quantity as entropy.

\section{The Origin of such defects:}

During the first half of the 19th Century, owing to the increasing experience, it has gradually become clear that the idea of the heat conservation adopted by Carnot and others ought to be untenable. This prompted $R$. Clausius in 1850 to conceptually reorganize the field of thermodynamics by assuming that heat and work are mutually interconvertible. As a part of his re-modeling, $R$. Clausius had introduced the quantity $S$, the entropy, to be able to formally describe the constraints inherent to such an interconversion."
Interestingly, all this clearly looks like a serious philosophical question - in the French-speaking literature, both the well-known French philosopher, Louis Rougier [122] and the prominent Swiss physicist, a formal teacher of Albert Einstein, Charles-Eugène Guye [123] have published very instructive books discussing philosophical problems of physics and chemistry, as a whole - and thermodynamics, in particular. Apart from this, both phenomenological and philosophical ways of generalizing the Basic Second Law from the Becker's standpoint a) were independently considered in detail by the prominent Russian physicist, Orest Daniilovich Khvol'son as well [124, 125], who could clearly show that the only entropy generalization attempt known at his time, namely the "heat death of the universe" leads to a logical blind alley. Moreover, he considers in detail the notion of 'compensation' ...

... Specifically, as Khvol'son puts in detail [125], there ought to be a fundamental difference between spontaneous processes, which don't require any special triggering (he denotes such processes as 'positive' ones), as well as those anyhow triggered, induced (he denotes them as 'negative' ones). With this in mind, any realistic natural process could in principle be construed as a specific set of the 'positive' and 'negative' processes which compensate (notabene !) each other ...

... On the other hand, would the Becker's trains of thoughts a) and b) be the only logical ways to interpret the interrelationship between irreversible processes and their corresponding entropies ? Fortunately - not at all !

Specifically, if we observe a correlation between some phenomena $A$ and $B$, the conventional interpretation would be to introduce the cause-andeffect relationship between $A$ and $B$ - and there are two variants: a) $A$ causes $B$; b) $B$ causes $A$. But it is also logically possible to introduce some (contingently latent) phenomenon $\mathrm{C}$ which is somehow closely connected to both $A$ and $B$ - and thus explains the observable $A<->B$ correlation. This is just the conceptual foundation of the so-called 'factor analysis of correlations' which was first introduced within the mathematical psychology $[126,127]$ and is presently well recognized in many fields both as a handy statistical method of multidimensional experimental data processing, as well as a powerful approach in working with theoretical concepts [128-135]. But here we would just like to make use of the pertinent 
correlation concept [126], to try revealing some latent factor(s) closely related to both entropy notion - and along with this - to irreversible processes, as they are.

... Now, to somehow clarify the concept, one should also recall the work by Ernst Mach, who was in his time very much - and very fruitfully - interested in finding the correct meaning of the Second Basic Law [136138]. First of all, E. Mach had published a short paper [136], where he would like to communicate his readership that the Second Basic Law "is not limited to heat phenomena, but could equally be applied to other natural phenomena as well, if the quantity of heat would be replaced by the relevant potential of some agent active during the process in question - and some corresponding potential function should also come instead of the absolute temperature.

Hence, the general rule we are looking for could then be formally expressed as follows:

When a particular potential value $P$ of some agent at the potential level $V$ gets transformed (e. g., if the potential of an electric discharge turns to heat), then there ought to be a simultaneous decrease in another potential value $P^{\prime}$ of the same agent from the higher potential level $V$ to the lower one, $V$ '.

Meanwhile, the above-mentioned quantities are connected to each other through the following equation:

$-\frac{P}{V}+P^{\prime}\left(\frac{1}{V^{\prime}}-\frac{1}{V}\right)=0$.

When applying the above expression, the main point is just what we should take as a potential (as the equivalent of the mechanical work) and what could be interpreted as the potential function. Of course, in the most of cases this has long been established, whereas in some other particular situations of interest it can be determined quite easily. For example, if we would like to apply the theorem expressed by Eq 8 to the impact of inert masses, then the 'vis viva', that is, the kinetic energy of the masses under study, should play the role of the 'potential', whereas their velocity might be regarded as the potential function. Thus, the masses moving with the same velocity aren't capable of exchanging the 'vis via' with each other - and this is why, they must be considered to stay at the same potential level."

And, regardless thereof, Felix Auerbach had added that Eq. 8 would only be correct for completely reversible processes - or the cycles like those introduced by Carnot. Since in such purely theoretical circular processes the initial and final states are absolutely the same, then after such a process basically nothing would happen with system as a the whole - and hence the total entropy should remain to be equal to zero.

And for realistic unidirectional processes the total entropy would not be zero - instead, according to the Second Basic Law, the latter must grow - until the 'process-promoting forces' (i. e., those stemming from the useful, usable, energy) are completely compensated by the 'entropic forces' (it would be definitely convenient to betoken such forces this way) and this ought to drive the system as a whole to its equilibrium state.

Furthermore, in his followed books $[137,138] \mathrm{E}$. Mach had analyzed in general and in great detail the actual physics behind Eq. 8. For this purpose he had referred to the fundamental work of Wilhelm Wundt [139]. In Wundt's book 'The physical axioms and their relationship to the principle of causality' are discussed and carefully analyzed in great detail. However, neither that time, nor at present, most physicists, chemists etc. would normally place references of such kind, since Wundt was - and still is - well known as the 'greatgrandfather of scientific psychology' (so, "please, what this particular field has to do with physics or chemistry ?") ... Well, alas, the latter reaction regrettably belongs to the general human psychology. A propos: there was and still is practically the same arrogance which had already come to light in the case of Julius Robert von Mayer - of course, of course, of course - but - Mayer was not a specially trained physicist or chemist, just only a practicing physician.

... Still, the W. Wundt's axioms are in fact of greatest interest, importance and weightiness for physics/chemistry - and E. Mach was definitely capable of recognizing this fact immediately.

W. Wundt had introduced a total of 6 axioms, which could be summarized as follows:

1. All types of causes in nature are connected with specific kinds of motion.

2. Every cause of a movement lies outside the moved object.

3. All causes of movements might be considered acting in the direction of the straight line 
connecting their source points and their points of application, respectively.

4. The effect of each cause is persevering.

5. Each action has a corresponding reaction.

6. Every effect is equivalent to its cause.

Further, according to W. Wundt, the principle of causality has a double meaning in any scientific research field. In part, it is considered the supreme law of all the possible events: 'Everything that happens has a cause', and partly it is also viewed as the supreme regulative of any scientific research and then it sounds as the 'principle of sufficient reason': 'Everything that happens has to be attributed to a particular cause which is enough to explain the happening'.

In addition, W. Wundt had also analyzed the correlations among the axioms introduced by him in detail. His conclusion: 'The last three axioms are clearly more general than the second and third ones, because the latter cannot properly define the quality of the natural causes' ...

... Now, 'armed' with W. Wundt's axioms, we might manage to interpret the Second Basic Law just in a straightforward way: Indeed, the entropy ought to be the total product of all pervasive, objectively existing counter-effects - or obstacles that are constantly and persistently trying to bring the successfully running process to a halt ... In other words, using the classification of O. D. Khvol'son [125], we might consider any realistic natural process as a pertinent combination of 'positive' and 'negative' sub-processes which compensate each other.

Interestingly: The first (and only one ?) colleague in the world who logically and productively followed the train of thoughts mentioned above, was, as far as we know, Georg Augustus Linhart (George Augustus Linhart) [140-142]. Although he presented no references to anyone of the above-mentioned colleagues, at least the most of the works discussed here was certainly familiar to him ... Linhart did not want to (or somehow could not ? ... If so, then it would definitely be such a shame !) publish his very interesting and important thoughts - so that all his rich mindset is now present only in the form of a number of 'dull' preprints ...

Understanding the conventional thermodynamics ...

We have already started to analyze the physicalchemical roots of the entropy-enthalpy compensation in detail, using the conventional train of thoughts embodied in the Eqs 3-7 above, so that, as a result, we were capable of elucidating the exact meaning of the both 'fitting' parameters in Eq 3, namely, the compensation temperature, $T_{c}$, and the ,energy' constant, $a[143,144]$. But the true zest of the whole story is that, in pursuing this way, we ought to eventually arrive at the logical roots of the conventional - the (so-called) 'equilibrium' - thermodynamics as a whole, which seems for the present to be a truly unexpected result at the first glance ... Therefore, we plan to dwell on this interesting topic elsewhere.

\section{CONCLUSIONS}

... The long - and the short of it ...

1. The discovery of the so-called 'rule of W. Meyer and $H$. Neldel' should not be considered a 'delusion', or 'supernatural miracle', or 'definite error' - but a direct result of the hard work during many years and by many colleagues - both the well-known ones - and those remained quite unknown.

2. If the relevant experiments had been carefully thought over and correctly designed, if their results had been skillfully (i. e., statistically correctly) processed, then the observation of the Meyer-Neldel rule reveals a valid entropyenthalpy compensation - regardless of the particular nature of the process investigated (chemical, physical, biological, ... etc., etc.).

3. In such a way the entropy-enthalpy compensation shows the interplay between the two basic natural laws: the "conservation of energy" - and the "action-reaction dichotomy" (or, may perhaps, even better to denote it - the "action-reaction dialectics").

4. Natural 'effects' are most likely to 'feed on' respective energy conversion processes (i. e., as the energy cannot come up from nothing, it should be somehow prepared in advance - to be useful for the process in question).

5. The corresponding 'counter-effects' of any kind are ubiquitous and unavoidable - so, the entropy ought to denote the 'total amount' of the latter.

6. Hence, the valid entropy-enthalpy compensation should be one of the key findings for deciphering the actual mechanisms of the natural processes in question - in most efficient and detailed way. 
7. All the above reasoning should also be applicable to computer modeling of microscopic physico-chemical processes (i. e., to such widespread theoretical approaches as, for example, molecular dynamics and Monte Carlo simulations).

\section{REFERENCES}

[1] Linert W, Yelon A. Isokinetic Relationship - Preface. Monatsh Chem 2013; 144: 1-2. http://dx.doi.org/10.1007/s00706-012-0863-9

[2] Liu L, Guo QX. Isokinetic Relationship. Chem Rev 2001; 101: 673-95.

http://dx.doi.org/10.1021/cr990416z

[3] Cooper A, Johnson CM, Lakey JH, Nöllmann M. Heat Biophys Chem 2001; 93: 215-30. http://dx.doi.org/10.1016/S0301-4622(01)00222-8

[4] Cornish-Bowden A. Entropy-Enthalpy Compensation. J Biosci 2002; 27: 121-26. http://dx.doi.org/10.1007/BF02703768

[5] Constable FH. The Mechanism of Catalytic Decomposition. Proc Roy Soc London A 1925; 108: 355-78. http://dx.doi.org/10.1098/rspa.1925.0081

[6] Cremer E, Schwab G-M. Über einen möglichen Zusammenhang. Z Phys Chem A 1929; 144: 243.

[7] Schwab G-M. Über einen möglichen Zusammenhang. Z Phys Chem B 1929; 5: 406-12.

[8] Schwab G-M. About the Mechanism of Contact Catalysis. Adv Catal 1950; 2: 251-67. http://dx.doi.org/10.1016/S0360-0564(08)60380-6

[9] Gapon EN. Über die Abhängigkeit. Ukr Chem Z 1930; 5: 169-80 (in Russian).

[10] Zawadzki J, Bretsznajder S. Some Remarks on the Mechanism. Trans Faraday Soc 1938; 34: 951-59. http://dx.doi.org/10.1039/tf9383400951

[11] Meyer W, Neldel H. Über die Beziehungen. Z Techn Phys 1937; 18: 588-93.

[12] Meyer W. Elektronenleitung in festen chemischen Verbindungen. Z Elektrochem 1944; 50: 274-90.

[13] Pohl RW. Electron conductivity and Photochemical Processes. Proc Phys Soc 1937; 49: 3-31. http://dx.doi.org/10.1088/0959-5309/49/4S/301

[14] Pohl RW. Zusammenfassender Bericht. Phys Z 1938; 39: 3654.

[15] Friederich E, Sittig L. Herstellung und Eigenschaften von Nitriden. Z Anorg Allg Chem 1925; 143: 293-20. http://dx.doi.org/10.1002/zaac.19251430121

[16] Friederich E, Sittig L. Herstellung und Eigenschaften von Carbiden. Z Anorg Allg Chem 1925; 144: 169-89. http://dx.doi.org/10.1002/zaac.19251440118

[17] Friederich E, Sittig L. Herstellung und Eigenschaften hochschmelzender niederer Oxyde. Z Anorg Allg Chem 1925; 145: 127-40.

http://dx.doi.org/10.1002/zaac.19251450109

[18] Friederich E, Sittig L. Über die Schmelzpunkte anorganischer Verbindungen und die der Elemente. Z Anorg Allg Chem 1925; 145: 251-76. http://dx.doi.org/10.1002/zaac. 19251450116

[19] Friederich E. Über bisher unbekannte Eigenschaften einfacher Verbindungen. Z Phys 1925; 31: 813-26. http://dx.doi.org/10.1007/BF02980635

[20] Friederich E. Berichtigungen zu meiner Arbeit: Über bisher unbekannte Eigenschaften. Z Phys 1925; 34; 637. http://dx.doi.org/10.1007/BF01328509
[21] Friederich E. Über die Härte anorganischer Verbindungen und die der Elemente. Fortschr Chem Phys Phys Chem 1926; 18: 714-56.

[22] Friederich E, Meyer W. Metallische Leitfähigkeit bei festen Halogeniden. Z Elektrochem 1926; 32: 566-76.

[23] Friederich E. Über eine Regel bei der elektrolytischen Leitfähigkeit fester Körper. Z Elektrochem 1926; 32: 576-77.

[24] Reis A. Über den Mechanismus der elektrolytischen Stromleitung in Kristallen. Z Phys 1927; 44: 353-58. http://dx.doi.org/10.1007/BF01391201

[25] Friederich E. Bemerkungen zu der Arbeit von Herrn Reis. Z Phys 1927; 45: 449. http://dx.doi.org/10.1007/BF01343066

[26] Reis A. Erwiderung auf die Bemerkung von E. Friederich. Z Phys 1927; 46: 444. http://dx.doi.org/10.1007/BF01390567

[27] Friederich E. Zur elektrolytischen Leitung fester Stoffe. Z Phys 1928; 48: 446. http://dx.doi.org/10.1007/BF01339129

[28] Friederich E. Die physikalischen Eigenschaften des festen Zustands als Wirkungen der chemischen Bindung. Tech Wiss Abh OSRAM Konz 1930; 1: 335-42.

[29] Saito G, Yoshida Y. Frontiers of Organic Conductors and Superconductors. Top Curr Chem 2012; 312: 67-26. http://dx.doi.org/10.1007/128 2011224

[30] Meyer W, Schmidt A. Messungen an Sperrschichtgleichrichtern. Z Tech Phys 1933; 14: 11-18.

[31] Meyer W, Über die Elektrizitätsleitung anorganischer Stoffe mit Elektronenleitfähigkeit. Z Phys 1933; 85: 278-93. http://dx.doi.org/10.1007/BF01342271

[32] Meyer W, Schmidt A. Über die Elektrizitätsleitung von Barium Oxyd. Tech Wiss Abh OSRAM Konz 1934; 3: 70-72.

[33] Meyer W, Berg H. Urandioxyd als Widerstandskörper für elektrische Geräte. Tech Wiss Abh OSRAM Konz 1934; 3 : 96-99.

[34] Meyer W. Beitrag zur Elektrizitätsleitung in Halbleiterwerkstoffen. Z Tech Phys 1935; 16: 355-61.

[35] Meyer W. Über die Elektrizitätsleitung anorganischer Stoffe/Halbleiterwerkstoffe. Tech Wiss Abh OSRAM Konz 1936; 4: 94-99.

[36] Hartmann W. Elektrische Untersuchungen an oxydischen Halbleitern. Z Phys 1936; 102: 709-33. http://dx.doi.org/10.1007/BF01338539

[37] Hüttig GF. Das stöchiometrische Gesetz von den konstanten und multiplen Proportionen als Grenzgesetz. Hochschulwiss 1927; 4: 261-66.

[38] Hüttig GF. Das stöchiometrische Gesetz von den konstanten und multiplen Proportionen als Grenzgesetz. Hochschulwiss 1927; 4: 317-22.

[39] Hüttig GF. Das stöchiometrische Gesetz von den konstanten und multiplen Proportionen als Grenzgesetz. Hochschulwiss 1927; 4: 365-70.

[40] Gudden B. Elektrizitätsleitung in kristallisierten Stoffen unter Ausschluß der Metalle. Erg. Exakt. Naturwiss. 1924, 3, 116159; Elektrische Leitfähigkeit elektronischer Halbleiter. Erg Exakt Naturwiss 1934; 13: 223-56. http://dx.doi.org/10.1007/BFb0112007

[41] Wagner C. Zur elektrischen Leitfähigkeit. Phys Z 1931; 32 641.

[42] Heisenberg W. Zum Paulischen Ausschließungsprinzip. Ann Phys 1931; 10: 888.

http://dx.doi.org/10.1002/andp.19314020710

[43] Peierls R. Elektronentheorie der Metalle. Erg Exakt Naturwiss 1932; 11: 264-22.

http://dx.doi.org/10.1007/BFb0111800 
[44] Gudden B. Zur elektrischen Leitfähigkeit. Erlangener Ber 1930; 62: 289.

[45] Gudden B. Zur elektrischen Leitfähigkeit. Phys Z 1934; 13: 223.

[46] Gudden B, Schottky W. Zur elektrischen Leitfähigkeit. Z Tech Phys 1935; 16: 323.

[47] Wagner C. Zur elektrischen Leitfähigkeit. Z Phys Chem 1931; Bodenstein-Festband 177.

[48] Wagner C. Zur elektrischen Leitfähigkeit. Z Phys Chem B $1933 ; 21 ; 42$.

[49] Wagner C. Zur elektrischen Leitfähigkeit. Z Phys Chem B 1933; 22: 181.

[50] Wagner C. Zur elektrischen Leitfähigkeit. Z Tech Phys 1935; 16: 327.

[51] Schottky W. Zur elektrischen Leitfähigkeit. Z Elektrochem 1939; 45: 49.

[52] Wilson AH. The Theory of Electronic Semiconductors. Proc Roy Soc London A 1931; 133: 458-91. http://dx.doi.org/10.1098/rspa.1931.0162

[53] Wilson $\mathrm{AH}$. The Theory of Electronic Semiconductors. Proc Roy Soc London A 1931; 134: 277-87. http://dx.doi.org/10.1098/rspa.1931.0196

[54] Wilson AH. A Note on the Theory of Rectification. Proc Roy Soc London A 1932; 136: 487-98. http://dx.doi.org/10.1098/rspa.1932.0097

[55] Pick H. Über die Farbzentren. Ann Phys 1939; 35: 73-83. http://dx.doi.org/10.1002/andp.19394270106

[56] Fowler RH. An Elementary Theory of Electronic Semiconductors. Proc Roy Soc London A 1933; 140: 505-22. http://dx.doi.org/10.1098/rspa.1933.0085

[57] Fowler RH. Notes on Some Electronic Properties of Conductors and Insulators. Proc Roy Soc London A 1933; 141: 56-71.

http://dx.doi.org/10.1098/rspa.1933.0103

[58] Meyer W. Urdox-Widerstände. Arch Tech Mess 1938; Z1173.

[59] Friederich E, Meyer W. Current Rectifier. Patent GB297822 1929.

[60] Busch G. Die elektrische Leitfähigkeit des Siliziumkarbids. Helv Phys Acta 1946; 19: 167-88.

[61] Busch G. Zusammenhang zwischen der Mengenkonstanten und der thermischen Aktivierungsenergie. Helv Phys Acta 1946; 19: 189-98.

[62] Busch G. Elektronenleitung in Nichtmetallen. Z Angew Math Phys 1950; 1: 3-31; 81-110. http://dx.doi.org/10.1007/BF02008886

[63] Gisolf JH. Die Temperaturabhängigkeit des Widerstandes von Halbleitern. Ann Phys 1947; 1: 3-26.

http://dx.doi.org/10.1002/andp.19474360103

[64] Gisolf JH. Bernhard Friedrich Adolf Gudden. Arch Elektr Übertr 1949; 3: 111-12.

[65] Keyes RW. Volumes for Activation for Diffusion in Solids. J Chem Phys 1958; 29: 467-75. http://dx.doi.org/10.1063/1.1744525

[66] Lawson AW. Diffusion of Impurities in Amorphous Polymers. J Chem Phys 1960; 32: 131-32. http://dx.doi.org/10.1063/1.1700886

[67] Van Vechten JA, Thurmond CD. Entropy of Ionization and Temperature Variation of Ionization Levels. Phys Rev B 1976; 14: 3539-50. http://dx.doi.org/10.1103/PhysRevB.14.3539

[68] Dosdale T, Brook RJ. Cationic Conduction and Diffision and the Compensation Law. J Mater Sci 1978; 13: 167-72. http://dx.doi.org/10.1007/BF00739287
[69] Roberts GG. Two Mechanisms to Explain Meyer-Neldel Rule. J Phys C: Solid State Phys 1971; 4: 3167-76. http://dx.doi.org/10.1088/0022-3719/4/18/021

[70] Many A, Harnik E, Gerlich D. On the Semiconductivity of Crystalline Aromatic Substances. J Chem Phys 1955; 23: 1733-34.

http://dx.doi.org/10.1063/1.1742440

[71] Rosenberg B, Kemeny G, Switzer RC. Hamilton, Th. C., Nature 1971; 232: 471-73. http://dx.doi.org/10.1038/232471a0

[72] Weichman FL, Kuzel R. Influence of Annealing on the Electrical Conductivity. Can J Phys 1970; 48: 63-69. http://dx.doi.org/10.1139/p70-010

[73] Linert W, Jameson RF. The Isokinetic Relationship. Chem Soc Rev 1989; 18: 477-505. http://dx.doi.org/10.1039/cs9891800477

[74] Yelon A, Movaghar B, Crandall RS. Multiexcitation Entropy. Rep Prog Phys 2006; 69: 1145-94.

http://dx.doi.org/10.1088/0034-4885/69/4/R04

[75] De Marco D, Linert W. Thermodynamic Relationships. J Chem Thermodyn 2002; 34: 1137-49.

http://dx.doi.org/10.1006/jcht.2002.0970

[76] Starikov EB, Nordén B. Entropy-Enthalpy Compensation. J Phys Chem B 2007; 111: 14431-35.

http://dx.doi.org/10.1021/jp075784i

[77] Starikov EB, Nordén B. In: Current Microscopy Contributions to Advances in Science and Technology, Méndez-Vilas A, Ed. Formatex Research Center, Spain 2012; vol. 2: pp. 1492-1503. http://www.formatex.info/microscopy5/book/14921503.pdf

[78] Thermodynamik. http://www.chemie.de/lexikon/Thermodynamik.html

[79] Jaynes ET. 'The Evolution of Carnot's Principle': The opening talk at the EMBO Workshop on maximum entropy methods in $\mathrm{x}$-ray crystallographic and biological macromolecule structure determination, Orsay, France, April 24-28 1984. Reprinted in: Ericksen \& Smith 1988; vol. 1: pp. 267-282. Its copy is available online for free.

[80] Auerbach F, Kanon der Physik: Die Bergriffe, Principien, Sätze, Formeln, Dimensionsformeln und Konstanten der Physik nach dem neuesten Stande der Wissenschaft systematisch dargestellt. Veit, Leipzig 1899.

[81] Auerbach F. Die Weltherrin und ihr Schatten. Ein Vortrag über Energie und Entropie. G. Fischer, Jena 1902.

[82] Auerbach F. Ektropismus und die physikalische Theorie des Lebens. Wilhelm Engelmann, Leipzig 1910.

[83] Wald F. Die Energie und ihre Entwertung, Wilhelm Engelmann, Leipzig 1889.

[84] Swinburne J. Entropy; or Thermodynamics from an Engineer's Standpoint and the Reversibility of Thermodynamics, E. P. Dutton \& Co., N. Y., USA 1904.

[85] Kollath W. Die Ordnung unserer Nahrung. Grundlagen einer dauerhaften Ernährungslehre, Stuttgart 1942.

[86] Schrödinger E. Was ist Leben? Die lebende Zelle mit den Augen des Physikers betrachtet, Leo Lehnen Verlag, München 1951.

[87] Brillouin L. Science and Information Theory, Academic Press, New York 1956.

[88] Ho M-W. What is Schrödinger's Negentropy? Mod Trends Thermokinet 1994; 3: 50-61.

[89] Nahin PJ. Oliver Heaviside: the life, work, and times of an electrical genius of the Victorian age, The Johns Hopkins University Press, Baltimore and London 2002.

[90] Perry J. The Entropy Diagram. Nature 1899; 60: 3-5. http://dx.doi.org/10.1038/060003a0 
[91] Perry J. Thermodynamics of Heat Engines. Nature 1903; 67: 602-605.

http://dx.doi.org/10.1038/067602a0

[92] Perry J. Entropy. Nature 1904; 69: 561-64. http://dx.doi.org/10.1038/069561a0

[93] Swinburne J, Perry J. Entropy. Nature 1904; 70: 54-55. http://dx.doi.org/10.1038/070054b0

[94] Bertrand J. Thermodynamique, Imprimeur-Libraire GauthierVillars, Paris 1887.

[95] Neumann C. Bemerkungen zur mechanischen Theorie der Wärme. Leipziger Ber Math-Naturwiss Klasse 1891; 43: 73156.

[96] Wesendonck K. von, Zur Thermodynamik. Ann Phys 1899; 303: 444-451; 305, 809-833.

[97] Planck M. Zur Abhandlung des Herrn K. Wesendonck Ann Phys 1900; 306: 621-24. http://dx.doi.org/10.1002/andp.19003060315

[98] Wesendonck K. von, Weiteres zur Thermodynamik. Ann Phys 1900; 307: 746-56. http://dx.doi.org/10.1002/andp. 19003070807

[99] Wiedeburg O. Zum zweiten Hauptsatz der Thermodynamik. Ann Phys 1901; 310: 514-47. http://dx.doi.org/10.1002/andp.19013100704

[100] Wesendonck K. von, Zur Arbeit von Herrn Wiedeburg. Ann Phys 1902; 312: 576-83; Über die Ungleichung von Clausius. Ann Phys 1902; 314: 1133-37.

[101] Wesendonck K. von, Zur Thermodynamik. Ann Phys 1905; 321: 558-64. http://dx.doi.org/10.1002/andp.19053210308

[102] Lorenz H. Lehrbuch der Technischen Physik 2. Band Technische Wärmelehre, Verlag R. Oldenbourg, München und Berlin 1904

[103] Weinstein MB. Einleitung in die höhere mathematische Physik, Ferd. Dümmler, Berlin 1901.

[104] Emden JR. Why do We Have Winter Heating? Nature 1938; 141: 908-909. http://dx.doi.org/10.1038/141908a0

[105] Sommerfeld A. Thermodynamik und Statistik, Harri Deutsch, Thun, Frankfurt/M 1977.

[106] Kubo R. Thermodynamics, North-Holland, Amsterdam, Wiley, New York 1968.

[107] Zeh HD. Entropie, Fischer Kompakt, Frankfurt/M 2005.

[108] Volkenstein MV. Entropy and Information (in Russian), Nauka, Moscow 1986.

[109] Shinoda K. "Iceberg" Formation and Solubility. J Phys Chem 1977; 81: 1300-302.

[110] Oparin EG. Physical Foundations of Fuel-Free Energetics (Limitations of the Second Law of Thermodynamics) (in Russian), Izdatelstvo LKI, Moscow 2007.

[111] Landsberg PT. Thermodynamics and Statistical Mechanics, Oxford University Press, Oxford 1978.

[112] Alekseev GN. Energy and Entropy (in Russian), Znanie, Moscow 1978.

[113] Falk G, Ruppel W. Energie und Entropie. Eine Einführung in die Thermodynamik, Springer-Verlag, Berlin, Heidelberg, New York 1976.

[114] Farkas J. Vereinfachte Ableitung des Carnot-Clausius'schen Satzes. Math Naturwiss Ber Ungarn 1895; XII: 282-86.

[115] Buckingham E. Note on the Theorem of Clausius. Phys Rev (Series I) 1896; 4: 39-49. http://dx.doi.org/10.1103/PhysRevSeriesl.4.39

[116] Buckingham E. An Outline of the Theory of Thermodynamics, MacMillan Company, London, New York 1900.
[117] Carathéodory C. Untersuchungen über die Grundlagen der Thermodynamik. Math Ann 1909; 67: 355-86. http://dx.doi.org/10.1007/BF01450409

[118] Carathéodory C. Über die Bestimmung der Energie. Sitzungsber. Preuss. Akad. Wiss. Berlin 1925; 39-47.

[119] Lavenda BH. Statistical Physics. A Probabilistic Approach, John Wiley \& Sons, New York, Chichester, Brisbane, Toronto, Singapore 1991.

[120] Becker R. Theorie der Wärme, Springer, Heidelberg 1985.

[121] Herrmann F, Job G. Altlasten der Physik, Aulis Verlag Deubner, Köln 2002.

[122] Rougier L. En marge de Curie, de Carnot et d'Einstein: études de philosophie scientifique, Étienne Chiron, Éditeur, Paris 1921.

[123] Guye, Ch.-Eug., L'Évolution physico-chimique - La relativité d'Einstein dans la classification des sciences - L'Évolution physico-chimique et les probabilités - Le principe de Carnot envisagé dans les organismes vivants, Étienne Chiron, Éditeur, Paris 1922; Guye, C.-E., Physico-chemical Evolution, Methuen \& Co. Ltd., London 1925.

[124] Chvolson OD. Hegel, Haeckel, Kossuth und das zwölfte Gebot: eine kritische Studie, Vieweg, Braunschweig 1906.

[125] Chvolson OD. Lehrbuch der Physik. Band I. Mechanik Einige Messinstrumente und Messmethoden. Die Lehre von den Gasen, Flüssigkeiten und festen Körpern. Band III, 1. und 2. Abteilung. Die Lehre von der Wärme, Vieweg, Braunschweig 1902-1904, 1922.

[126] Spearman C. The Proof and Measurement of Association between Two Things. Am J Psych 1904; 15: 72-101.

[127] Spearman C. "General Intelligence", Objectively Detemined and Measured. Am J Psych 1904; 15: 201-92.

[128] Burt C. The Factors of the Mind, University of London Press, London 1940.

[129] Rummel RJ. Understanding Factor Analysis. J Confl Resol 1967; 11: 444-80.

[130] Basilevsky AT. Statistical Factor Analysis and Related Methods: Theory and applications, John Wiley \& Sons, New York, Chichester, Brisbane, Toronto, Singapore 1994. http://dx.doi.org/10.1002/9780470316894

[131] Jöreskog KG, Reyment RA. Applied Factor Analysis in the Natural Sciences, Cambridge University Press, Cambridge 1996.

[132] Marcoulides GA, Moustaki I, Eds., Latent Variable and Latent Structure Models, Lawrence Erlbaum Associates Publisher, Mahwah, New Jersey, London 2002.

[133] Thompson B. Exploratory and Confirmatory Factor Analysis Understanding Concepts and Applications, American Psychological Association, Washington 2004.

[134] Brown TA. Confirmatory Factor Analysis for Applied Research, Guilford Press, New York, London 2006.

[135] Harrington D. Confirmatory Factor Analysis: Pocket Guides to Social Work Research Methods, Oxford University Press, Oxford 2009.

[136] Mach E. Eine Bemerkung über den 2. Hauptsatz der mechanischen Wärmetheorie. LOTOS 1871; 21: 17-18.

[137] Mach E. Die Geschichte und die Wurzel des Satzes von der Erhaltung der Arbeit, J. G. Calve'sche, Prag 1872.

[138] Mach E. Die Prinzipien der Wärmelehre: Historisch-kritisch entwickelt, J. A. Barth, Leipzig 1896.

[139] Wundt W. Die physikalischen Axiome und ihre Beziehung zum Causalprincip, F. Enke Verlag, Erlangen 1866.

[140] Starikov EB. Many Faces of Entropy. ChemPhysChem 2010; 11: 3387-94.

http://dx.doi.org/10.1002/cphc.201000583 
[141] Starikov EB. George Augustus Linhart. World J Cond Matt Phys 2012; 2: 101-16.

[142] Starikov EB. Entropy is Anthropomorphic. Monatsh Chem 2013; 144: 97-102.

http://dx.doi.org/10.1007/s00706-012-0837-y
[143] Starikov EB. Entropy-Enthalpy Compensation and its Significance - in Particular for Nanoscale Events. J Appl Solution Chem Model 2013; 2: 126-35.

[144] Starikov EB. Valid Entropy-Enthalpy Compensation: Its True Physical-Chemical Meaning. J Appl Solution Chem Model 2013; 2: 240-45.

Received on 18-12-2013

Accepted on 17-02-2014

Published on 17-03-2014

DOI: http://dx.doi.org/10.6000/1929-5030.2014.03.01.3

(C) 2014 E.B. Starikov; Licensee Lifescience Global.

This is an open access article licensed under the terms of the Creative Commons Attribution Non-Commercial License (http://creativecommons.org/licenses/by-nc/3.0/) which permits unrestricted, non-commercial use, distribution and reproduction in any medium, provided the work is properly cited. 